\title{
How to improve the quality of care for women with postpartum haemorrhage at Onandjokwe Hospital, Namibia: quality improvement study
}

Tshimanga Nsangamay and Robert Mash ${ }^{*}$

\begin{abstract}
Background: Postpartum haemorrhage (PPH) is the leading direct cause of maternal morbidity and mortality worldwide. The sustainable development goals aim to reduce the maternal mortality ratio to 70 per 100,000 live births. In Namibia, the ratio was reported as 265 per 100,000 live births in 2015 and yet little is published on emergency obstetric care. The majority of deliveries in Namibia are facility-based. The aim of this study was to assess and improve the quality of care for women with PPH at Onandjokwe Hospital, Namibia.

Methods: A criterion-based audit cycle in all 82 women with PPH from 2015 using target standards for structure, process and outcomes of care. The audit team then planned and implemented interventions to improve the quality of care over a 10-month period. The audit team repeated the audit on all 70 women with PPH from the same 10month period. The researchers compared audit results in terms of the number of target standards achieved and any significant change in the proportion of patients' care meeting the predetermined criteria.

Results: In the baseline audit 12/19 structural, 0/9 process and 0/3 outcome target standards were achieved. On follow up 19/19 structural, 6/9 process and 2/3 outcome target standards were met. There was one maternal death in the baseline group and none in the follow up group. Overall 6/9 process and 2/3 outcome criteria significantly improved $(p<0.05)$ from baseline to follow up. Key interventions included training of nursing and medical staff in obstetric emergencies, ensuring that guidelines and standard operating protocols were easily available, reorganising care to ensure adequate monitoring of women postpartum and ensuring that essential equipment was available and functioning.

Conclusion: The study demonstrates that the quality of care for emergency obstetrics can be improved by audit cycles that focus on the structure and process of care. Other hospitals in Namibia and the region could adopt the process of continuous quality improvement and similar strategies.
\end{abstract}

Keywords: Postpartum haemorrhage, Quality of care, Maternal mortality, Emergency care, Namibia

\footnotetext{
* Correspondence: rm@sun.ac.za

Division of Family Medicine and Primary Care, Stellenbosch University,

Stellenbosch, South Africa
}

(c) The Author(s). 2019 Open Access This article is distributed under the terms of the Creative Commons Attribution 4.0 International License (http://creativecommons.org/licenses/by/4.0/), which permits unrestricted use, distribution, and reproduction in any medium, provided you give appropriate credit to the original author(s) and the source, provide a link to the Creative Commons license, and indicate if changes were made. The Creative Commons Public Domain Dedication waiver (http://creativecommons.org/publicdomain/zero/1.0/) applies to the data made available in this article, unless otherwise stated. 


\section{Background}

Postpartum haemorrhage (PPH) is the leading direct cause of maternal morbidity and mortality worldwide $[1,2]$. The condition contributes to $20 \%$ of maternal mortality globally and affects $2 \%$ of all women who give birth [3-5].

The Maternal Mortality Ratio (MMR) is an important indicator of the maternal health status within a given population [6]. The MMR in many African countries (510 per 100,000 live births for Africa in 2013) is very high and obstetric haemorrhage accounts for more than one quarter of maternal deaths $[7,8]$. The Millennium Development Goals aimed to reduce maternal mortality by three-quarters by 2015. The World Health Organization (WHO) indicated that reducing deaths from $\mathrm{PPH}$ by $75 \%$ would enable this target to be achieved $[8,9]$. Many Sub-Saharan countries unfortunately failed to achieve the goal by the end of 2015, and the annual number of maternal deaths remains very high [8]. The United Nations has launched a global strategy (2016-2030) for women's, children's and adolescent's health to complete the unfinished work of the Millennium Development Goals. The strategy aims to address inequities within and between countries and to help countries begin implementing the 2030 Sustainable Development Goals in which one of the specific objective is to reduce the global MMR to less than 70 per 100,000 live births [10].

Maternal deaths due to PPH have increased in many countries and underlying factors such as increasing maternal age, caesarean section rates and multiple pregnancies have been identified $[1,11-15]$. Women in low and middle income countries have an increased likelihood of severe haemorrhage and of dying from PPH-related complications [16].

In Namibia, the MMR increased from 338 maternal deaths per 100,000 live births in 1990 to 390 maternal deaths per 100,000 live births in 2005 [17]. However, the MMR has subsequently improved and was reported as 265 per 100,000 live births in 2015, although this is still far above the target of 70 per 100,000 live births $[17,18]$. This means that for every 1000 live births in Namibia about three women die during pregnancy, childbirth, or within 2 months of childbirth.

According to the WHO, $\mathrm{PPH}$ is defined as a blood loss greater than or equal to $500 \mathrm{ml}$ within $24 \mathrm{~h}$ after birth, while massive PPH is a blood loss greater than $1000 \mathrm{ml}$. Bleeding within $24 \mathrm{~h}$ after birth is considered to be primary PPH, while secondary PPH is observed from $24 \mathrm{~h}$ up to 12 weeks after birth [9]. Primary PPH may be caused by an atonic uterus, trauma to the birth canal as well as rare causes such as uterine inversion or clotting defects [19].

The intrapartum risk factors for PPH are induction of labour, augmentation of labour by oxytocin, prolonged or rapid labour, instrumental delivery and caesarean section. Women without risk factors can develop PPH or even conceal their bleeding internally, which is why healthcare workers should consider every woman to be at risk. More than $70 \%$ of maternal deaths due to obstetric haemorrhage are preventable and are due to substandard care $[11,15,20]$.

Active management of the third stage of labour can prevent $\mathrm{PPH}$. This includes actions to deliver the placenta and use of uterotonic medication within one minute of delivery, with oxytocin as the drug of choice. Controlled cord traction helps the placenta to separate from the uterus and descend into the vagina. These interventions can reduce the estimated maternal blood loss after birth by up to $66 \%$ when compared with physiological or expectant management [21].

Emergency care for PPH requires teamwork, increased awareness of the problem, and anticipatory clinical practice to prevent $\mathrm{PPH}$ or respond quickly and use of evidence based PPH guidelines [22]. To reduce the huge burden of PPH on maternal and child health there is a necessity to provide high quality care to women with this lethal condition. Quality care requires both facility readiness (availability of staff, key equipment, drugs supplies) and provider preparedness (knowledge and skills) for dealing with $\mathrm{PPH}$ [23]. Maternal deaths from $\mathrm{PPH}$ in Africa have been linked to poor quality of care and weak health systems. Key issues include the inability of midwives to institute life saving measures, failure to treat anaemia during antenatal care, delays in care due to poor inter-hospital transfer, difficulty accessing blood for transfusion, lack of essential medication and inadequate training of staff in obstetric emergencies [24-27].

Improving healthcare providers' knowledge and skills in emergency obstetric care and ensuring that the healthcare facility has essential lifesaving resources, have been identified as important factors that can impact on the high MMR in many African countries [28]. Significant event analysis of maternal deaths and near-misses can also identify practical measures for tackling care deficiencies and interventions to improve maternal care quality [29-32]. No studies on the quality of emergency obstetric care, including care for $\mathrm{PPH}$, have been published from Namibia.

The aim of this study was to assess and improve the quality of care for women with $\mathrm{PPH}$ at Onandjokwe Hospital, Namibia. The specific objectives were to assess the current quality of care for PPH; to plan and implement changes to improve the quality of care; and to assess if these changes were associated with a measurable improvement in the quality of care.

\section{Methods}

\section{Study design}

The study design was a quality improvement cycle (QIC) that followed six steps: the establishment of the QIC 
team, agreement on criteria and target standards, initial data collection, initial data analysis and feedback to the team, planning and implementation of interventions, repeat data collection and data analysis to detect change in the quality of care. Such criterion-based audit cycles have been well established as an approach to improving the quality of care [33] and have also shown particular value in reducing maternal and perinatal mortality [29]. The World Health Organization sees "clinical audit and feedback" as one of the key strategies for improving quality of clinical care and defines it as "a strategy to improve patient care through tracking adherence to explicit standards and guidelines coupled with provision of actionable feedback on clinical practice" [34].

\section{Setting}

Onandjokwe Hospital in northern Namibia, about 750 $\mathrm{km}$ from the capital city of Windhoek, was the study site. The hospital provided emergency obstetric care for the Onandjokwe district, which covered approximately $25,000 \mathrm{~km}^{2}$ and had a population of 147,000 , mostly from the Wambo ethnic group. It was also the nearest referral hospital for district hospitals in the Oshana and Ohangwena regions. There are two other such intermediate or regional hospitals in Namibia that serve their immediate communities and surrounding district hospitals.

The Department of Obstetrics and Gynaecology at Onandjokwe Hospital participated in the study. The department had a consultant obstetrician, four medical practitioners, two senior registered nurses, 26 registered nurses, six midwives and 16 enrolled nurses. The nursing staff worked in three shifts (morning shift 07h0013h00, afternoon shift 13h00-19h00 and night shift 19h00-07h00). In 2015 there were 6407 live births at the hospital.

The maternity services had 75 beds (antenatal care 11 beds, labour ward seven beds, delivery ward four beds and postnatal ward 53 beds). The hospital had a theatre unit with two operating rooms and a functioning laboratory under the Namibia Institute of Pathology.

\section{Study population}

The initial audit included all 82 women who delivered at Onandjokwe hospital and were diagnosed with primary PPH during 2015. The researcher identified women with PPH from the labour ward register and excluded women if they had a home delivery, developed PPH at another hospital or had a secondary PPH. The follow up audit included all 70 women who delivered at Onandjokwe and had a primary PPH between November 2016 and August 2017 (10 months). All women that presented with PPH during these time periods were included in the study and therefore there was no sampling involved within these time frames. No women were excluded from the study.

\section{Audit team}

The main researcher (first author) led the audit team, which included two senior doctors and three nurses from the maternity services.

\section{Target standards}

The audit team used the guideline for maternity care from South Africa and the guideline for management of $\mathrm{PPH}$ from South Africa to set up evidence-based criteria [35, 36]. The South African health system is similar to that in Namibia and they are neighbouring countries. The Namibian Ministry of Health and Social Services had not published a guideline on obstetric care [37]. The team agreed on measurable structural, process and outcome criteria, and set performance levels for each criterion that would be realistic goals for quality improvement in the local context.

\section{Structural target standards}

Structure refers to the resources needed to support quality care. These resources may be equipment, human resources or materials such as guidelines and protocols. The protocols referred to were more detailed instructions on management of conditions that were locally produced by the hospital and based on the recommendations in national guidelines. A score was used for each item: if the item existed and was functioning $=2$, if the item existed but was not fully functional $=1$, if the item did not exist $=0$. Target standards for structure were:

- $75 \%$ of medical officers in the maternity ward were trained in obstetric emergencies and neonatal resuscitation

- $50 \%$ of nurses in the maternity ward were trained in obstetric emergencies and neonatal resuscitation

- The labour ward had a piped water supply

- There was soap for hand washing in the labour ward

- The labour ward had a functioning electricity supply

- $75 \%$ of sphygmomanometers in labour ward were functioning

- There was a functioning haemoglobin meter

- There was a guideline for maternity care in the labour ward

- There was a guideline on management of PPH

- There was standard protocol for the management of the atonic uterus

- There was standard protocol for the manual removal of placenta

- There were standard blood requisition forms

- There were informed consent forms for blood transfusion 
- There were tubes for the collection of blood samples

- There were intravenous fluids (crystalloids and colloids)

- There were plastic bags for the collection of blood samples

- There were oxygen cylinders with regulators

- There were uterotonic medications (oxytocin and misoprostol)

- There were antibiotics available ( $\beta$ lactam and cephalosporin)

\section{Process target standards}

Process refers to the activities or behaviours expected of health professionals in their management of the patient. The target standards for the process were as follows:

- $80 \%$ of women were diagnosed with PPH within 45 min after delivery

- $90 \%$ of women with uterine atony were administered oxytocin within $5 \mathrm{~min}$ of diagnosis

- $90 \%$ of women received crystalloid fluids within 5 min of diagnosis of PPH

- $70 \%$ of women with uterine atony received uterine massage and bimanual compression if the uterus failed to contract despite oxytocin

- $50 \%$ of women with uterine atony received misoprostol within $25 \mathrm{~min}$ of determining failure of oxytocin

- $90 \%$ of women received prophylactic antibiotics after manual removal of placenta or uterine exploration

- $100 \%$ of women with low haemoglobin $(\leq 6 \mathrm{~g} / \mathrm{dl})$ received blood products

- $70 \%$ of women received blood products within 15 min after being diagnosed with a massive $\mathrm{PPH}$

- $75 \%$ of women with a massive PPH were managed surgically (hysterectomy) within $60 \mathrm{~min}$ of diagnosis or within $120 \mathrm{~min}$ after delivery

\section{Outcome target standards}

The target standards for the outcome were:

- $90 \%$ of women were treated and stabilized within $6 \mathrm{~h}$ of $\mathrm{PPH}$

- $100 \%$ of women survived the PPH

- $70 \%$ of women on discharge were given an appointment for follow up within 1 month

\section{Initial data collection}

The main researcher collected data from the patient's maternity record in both the labour and postnatal wards using a standardised collection tool to measure the process and outcome criteria. The date, time of events and clinical findings were all documented in the maternity record which allowed the time taken for different interventions to be calculated. The researcher also inspected the maternity services in order to measure the structural criteria and used a simple questionnaire to evaluate the proportion of healthcare workers trained in obstetric and neonatal emergency care.

\section{Initial data analysis}

The researcher captured the data in Microsoft Excel and checked for any omissions or errors. The researcher then used the Statistical Package for the Social Sciences version 25 to analyse the data. Frequencies and percentages described categorical data, while numerical data was summarised using means and standard deviations or median and interquartile ranges, depending on whether data were symmetrically distributed or skewed. The analysis compared results and target standards to determine the number of targets achieved at baseline.

\section{Planning and implementation of change}

The audit team reviewed the initial data analysis and the main researcher facilitated reflection by using the " 5 Whys" techniques to identify root causes of poor quality [33]. Once the team had reached a consensus on root causes their findings were presented to the Department of Obstetrics and Gynaecology for further discussion and revision. Following this, the audit team implemented changes to clinical practice over a period of 10 months (November 2016 to August 2017).

\section{Repeat data collection and data analysis}

The researcher then collected retrospective data on the same criteria in the patients seen during the 10-month period when clinical practice was changed. Data was again analysed descriptively to see if there was improvement in the number of target standards achieved. In addition, the Pearson's Chi-square test compared categorical data at baseline and follow up with a statistical significance at $p<0.05$.

\section{Results}

There were 152 files audited, 82 at the baseline audit and 70 at the re-audit. Table 1 presents a profile of the women included in the two audits. The participants' mean age for both audits was 29 years. The two groups differed significantly in terms of their parity and marital status, with the re-audit group having more multiparous and married women, however the causes of PPH were similar between the two groups. There were three patients who had both uterine atony and vaginal tears, but the PPH was attributed to the uterine atony.

\section{Structural target standards}

Table 2 compares the results for structural criteria at baseline and follow up. At baseline 12/19 (63\%) of target 
Table 1 Profile of mothers at baseline audit and re-audit

\begin{tabular}{llll}
\hline Variable & $\begin{array}{l}\text { Baseline } \\
N=82 \mathrm{n}(\%)\end{array}$ & $\begin{array}{l}\text { Re-audit } \\
N=70 \mathrm{n}(\%)\end{array}$ & $p$ value \\
\hline Parity & $34(41.5)$ & $18(25.7)$ & 0.041 \\
Primiparous & $48(58.5)$ & $52(74.3)$ & \\
Multiparous & & & \\
Marital status & $62(75.6)$ & $36(51.4)$ & 0.002 \\
Single & $20(24.4)$ & $34(48.6)$ & \\
Married & & & \\
Cause of postpartum & & & \\
haemorrhage & $17(20.7)$ & $12(17.1)$ & 0.317 \\
Tears & $13(15.9)$ & $18(25.7)$ & \\
Retained products of conception & $52(63.4)$ & $40(57.1)$ & \\
Atony & & &
\end{tabular}

Table 2 Results for structural target standards

\begin{tabular}{|c|c|c|}
\hline \multirow[t]{2}{*}{ Structural target standards } & \multicolumn{2}{|l|}{$\begin{array}{l}\text { Standard } \\
\text { achieved }\end{array}$} \\
\hline & Baseline & Re-audit \\
\hline $\begin{array}{l}75 \% \text { of medical officers in maternity ward are } \\
\text { trained in obstetric emergencies and neonatal } \\
\text { resuscitation }\end{array}$ & No & Yes \\
\hline $\begin{array}{l}50 \% \text { nurses in maternity ward are trained in } \\
\text { obstetric emergencies and neonatal resuscitation }\end{array}$ & No & Yes \\
\hline The labour ward has a piped water supply & Yes & Yes \\
\hline There is a soap for hand washing in labour ward & Yes & Yes \\
\hline The labour ward has functioning electricity & Yes & Yes \\
\hline $\begin{array}{l}75 \% \text { of blood pressure machines in labour ward } \\
\text { are functioning }\end{array}$ & No & Yes \\
\hline There is a functioning haemoglobin meter & Yes & Yes \\
\hline $\begin{array}{l}\text { There is a guideline for maternity care in labour } \\
\text { ward }\end{array}$ & No & Yes \\
\hline There is a guideline on management of $\mathrm{PPH}$ & No & Yes \\
\hline $\begin{array}{l}\text { There is standard protocol for the management } \\
\text { of the atonic uterus }\end{array}$ & No & Yes \\
\hline $\begin{array}{l}\text { There is standard protocol for the manual } \\
\text { removal of placenta }\end{array}$ & No & Yes \\
\hline There are standard blood requisition forms & Yes & Yes \\
\hline $\begin{array}{l}\text { There are informed consent forms for blood } \\
\text { transfusion }\end{array}$ & Yes & Yes \\
\hline $\begin{array}{l}\text { There are cross match tubes for the collection } \\
\text { of blood sample }\end{array}$ & Yes & Yes \\
\hline $\begin{array}{l}\text { There are intravenous fluids } \\
\text { (crystalloids and colloids) }\end{array}$ & Yes & Yes \\
\hline $\begin{array}{l}\text { There are plastic bags for the collection of } \\
\text { cross match sample and blood requisition } \\
\text { forms }\end{array}$ & Yes & Yes \\
\hline There is an oxygen cylinder with regulator & Yes & Yes \\
\hline $\begin{array}{l}\text { There are uterotonic medications (oxytocin, } \\
\text { misoprostol) }\end{array}$ & Yes & Yes \\
\hline There are antibiotics ( $\beta$ lactam, cephalosporins) & Yes & Yes \\
\hline
\end{tabular}

standards were achieved, while 19/19 (100\%) were achieved at re-audit. The number of medical officers and nurses trained in obstetric emergencies and neonatal resuscitation increased from $2 / 4(50.0 \%)$ and $1 / 46(2.2 \%)$ respectively to $3 / 4(75.0 \%)$ and $27 / 50(54.0 \%)$, while the number of functioning sphygmomanometers increased from $1 / 4(25.0 \%)$ to $4 / 4(100.0 \%)$.

\section{Process target standards}

Table 3 compares the results for process criteria at baseline and follow up. At baseline, none of the standards were achieved, but six out of nine were achieved at reaudit and six of the nine criteria significantly improved. All criteria either achieved the target standard or improved significantly.

\section{Outcome target standards}

There was one maternal death at baseline and no maternal deaths at re-audit. Table 4 compares the results for the other outcome criteria at baseline and follow up. None of the standards were achieved at baseline, while two of the three standards were achieved at re-audit and two criteria significantly improved.

\section{Changes and implementation of changes}

The audit team and departmental staff identified that there was a lack of training of the professional staff in the labour ward to manage obstetric emergencies and that the staff did not have access to an evidence-based guideline and protocols. Key equipment, such as sphygmomanometers, were also not maintained or calibrated. They also identified that women with PPH were not diagnosed quickly due to a lack of effective monitoring post-partum. They made recommendations to address the poor performance observed in the baseline audit. The implementation of changes engaged all doctors and nurses involved in patient care at the maternity ward. Table 5 describes the interventions to improve care of $\mathrm{PPH}$.

\section{Discussion}

Significant improvements in the structure, process and outcomes of care for PPH required relatively simple interventions. After the interventions all structural standards were met and all process and outcome standards either met the target standard or significantly improved.

Structural interventions included the availability of essential equipment, clinical guidelines and the training of staff, while process interventions included the reorganisation of the labour and postnatal wards for women in the fourth stage of labour in order to monitor them closely. As a result, outcomes significantly improved such as the time taken to diagnose $\mathrm{PPH}$ and the percentage of women stabilised within 6-h. Reducing the 
Table 3 Results for process target standards

\begin{tabular}{|c|c|c|c|}
\hline Process target standards & Baseline $n(\%)$ & Re-audit n (\%) & $p$ value \\
\hline $80 \%$ of women diagnosed with PPH within 45 min after delivery & 30/82 (36.6) & $55 / 70(78.6)$ & $<0.001$ \\
\hline $\begin{array}{l}90 \% \text { of women with uterine atony have been administered oxytocin within } 5 \text { min of } \\
\text { diagnosis }\end{array}$ & 29/52 (55.8) & $33 / 40(82.5)$ & 0.015 \\
\hline $90 \%$ of women received intravenous crystalloid fluid within 5 min of diagnosis of PPH & $38 / 82(46.3)$ & $65 / 70(92.9)$ & $<0.001$ \\
\hline $\begin{array}{l}70 \% \text { of women with uterine atony received uterine massage and bimanual compression if } \\
\text { the uterus failed to contract despite oxytocin }\end{array}$ & 21/52 (40.3) & $30 / 40(75.0)$ & 0.002 \\
\hline $\begin{array}{l}50 \% \text { of women with uterine atony were administered misoprostol within } 25 \text { min of } \\
\text { determining failure of oxytocin }\end{array}$ & $8 / 39(20.5)$ & 28/36 (77.8) & $<0.001$ \\
\hline $\begin{array}{l}90 \% \text { of women received prophylactic antibiotics after manual removal of placenta or } \\
\text { uterine exploration }\end{array}$ & 10/13 (76.9) & 17/18 (94.4) & 0.151 \\
\hline $100 \%$ of women with low haemoglobin $(\leq 6 \mathrm{~g} / \mathrm{dl})$ received blood products & $54 / 55(98.2)$ & $36 / 36(100.0)$ & 0.416 \\
\hline $\begin{array}{l}\text { 70\% of women received blood products within } 15 \text { min of being diagnosed with a } \\
\text { massive PPH }\end{array}$ & $13 / 52(25.0)$ & $22 / 36(61.1)$ & 0.001 \\
\hline $\begin{array}{l}\text { 75\% of women with a massive PPH were managed surgically within } 60 \text { min after } \\
\text { being diagnosed or within } 120 \text { min of delivery }\end{array}$ & $2 / 5(40.0)$ & $3 / 3(100.0)$ & 0.196 \\
\hline
\end{tabular}

time it takes to receive skilled care in an adequately resourced healthcare facility has been linked to reduced deaths from obstetric haemorrhage [28, 30].

Many countries are implementing training programmes to improve healthcare workers knowledge and skills in managing obstetric emergencies. In South Africa the Essential Steps in Managing Obstetric Emergencies (ESMOE) and the Emergency Obstetric Simulation Training (EOST) have led to significant improvement in maternity care [38]. The South African inter-ministerial committees on maternal, perinatal and child mortality have also emphasised the need to ensure 24-h access to functioning emergency obstetric care, the provision of dedicated inter-facility transport, the development of maternity homes and standardised referral criteria [39]. In Uganda interventions such as training of healthcare workers, obstetric drills and displaying guidelines was also associated with improvements in the quality of care for patients with $\mathrm{PPH}$, severe pre-eclampsia and eclampsia [5].

Our study agrees with the Ugandan experience, which showed an improvement in the quality of care for $\mathrm{PPH}$ by the implementation of simple interventions. The sustainability of these interventions, however, requires the implementation of well-structured training programmes, equivalent to ESMOE and EOST, and strong leadership of the health system. Programmes that provide low-dose, high-frequency training in the workplace have been recommended [40] rather than longer workshops that take staff out of service delivery. ESMOE for example emphasises the need for regular "fire drills" to simulate emergency care in the clinical environment [38].

Healthcare workers diagnosed PPH by a visual estimation of blood loss. This could have been underestimated and the number of $\mathrm{PPH}$ cases might have been higher. The team included all women with PPH in the audits in order to minimise any sampling or selection bias and because total numbers were relatively small. The archiving of maternity records was relatively adequate, but 15 files were missing at baseline and nine files in the re-audit. It is possible that these additional files could have altered the findings if the data was available. The audit team noted one maternal death due to PPH in the baseline audit, but did not have access to the patient's file, which was in the regional offices for evaluation.

A limitation of the QIC is that there is no control group and it is not possible to prove a causal relationship between the change to clinical practice and improvement in quality of care. Improved quality is attributed to the change in clinical practice as there is a logical relationship between the proposed cause and effect. There were no other interventions that happened outside of the QIC during this period to provide an alternative explanation for the improved quality. It is possible that similar gaps in quality exist at the other intermediate referral hospitals and that the gap is even

Table 4 Results for outcome target standards

\begin{tabular}{lll}
\hline Outcome target standards & Baseline $N=82 \mathrm{n}(\%)$ & Re-audit $\mathrm{N}=70 \mathrm{n}(\%)$ \\
\hline $\begin{array}{l}90 \% \text { of women treated and stabilised from complication } \\
\text { of PPH within } 6 \mathrm{~h}\end{array}$ & $60(73.2)$ & $64(91.4)$ \\
$\begin{array}{l}70 \% \text { of women were given a follow up date within one } \\
\text { month of being discharged from hospital }\end{array}$ & $21(25.6)$ & $43(61.4)$ \\
\hline
\end{tabular}


Table 5 Summary of interventions to improve care of PPH

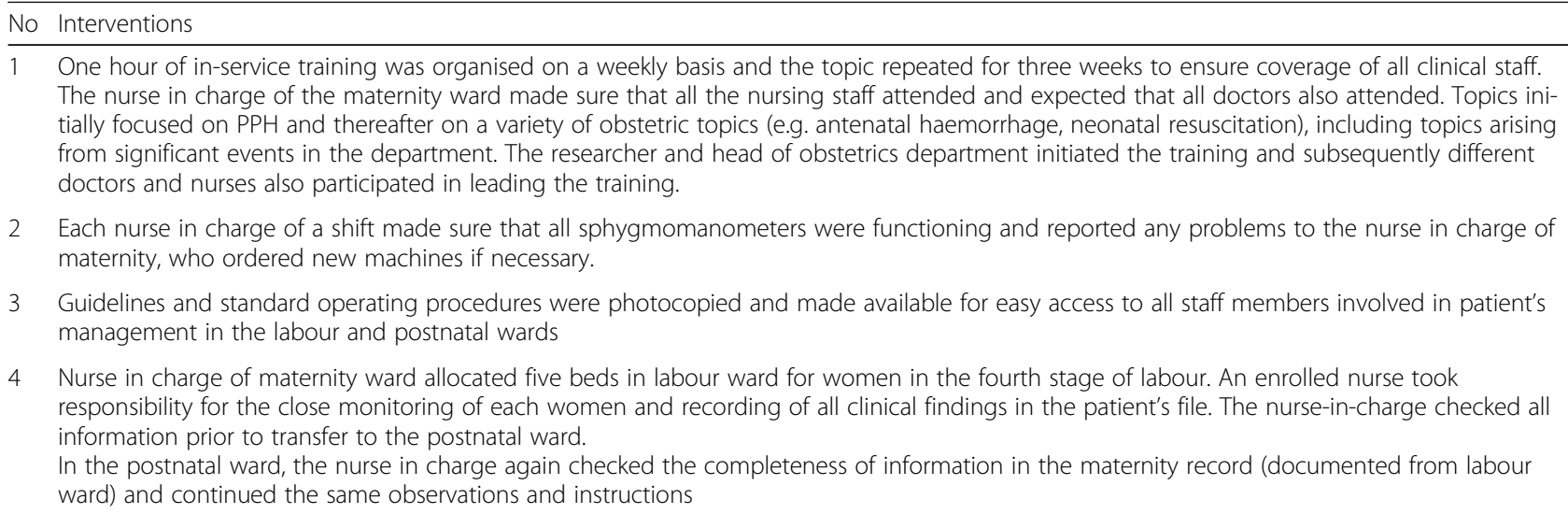

wider at district hospitals. The quality improvement process and lessons learnt may be transferable to these other hospitals.

A QIC is a continuous process and requires a commitment of all healthcare workers and the hospital's management to sustain and incrementally improve the quality of care over time. The completeness of information in the maternal record was part of the change to clinical practice and future audits could include a criteria to measure this. Hospitals should ensure that:

- They provide workplace-based training routinely to nursing, midwifery and medical staff and document attendance.

- Clinical guidelines and standard operating procedures are readily available on maternity wards

- All essential equipment and resources are available, regularly checked and maintained

- Clinical practice is organised to ensure close monitoring of women post-delivery in the labour and post-natal wards

- A learning environment is created with a focus on continuous quality improvement and measurement of target standards

This research contributes to the paucity of information on quality of care within Namibia and highlights structural and process criteria that are likely to be issues at other hospitals. There is a need for health systems to incorporate such quality improvement processes at scale and not to rely on ad hoc initiatives such as this at the local level [41]. This QIC demonstrates how relatively simple interventions, that do not require substantial additional or external resources, can lead to meaningful improvement to the competence of care and better outcomes for patients. The WHO describe a range of strategies for improving clinical care that include clinical audit and feedback and suggest the need for collaborative and team-based cycles that involve multiple teams across similar hospitals [34]. In addition they suggest the need for guidelines to support clinical decision-making and care pathways as well as morbidity and mortality reviews [34]. Such guidelines are needed in the Namibian context and strategies should be embedded in a clear policy on quality improvement.

\section{Conclusions}

The study demonstrates that the quality of care for emergency obstetrics can be improved by audit cycles that focus on the structure and process of care. The quality of care for women diagnosed with $\mathrm{PPH}$ in our healthcare setting was substandard and yet simple interventions led to significantly improvement. Key interventions included workplace-based training in obstetric emergencies, availability of guidelines and standard operating protocols, attention to the availability and functioning of essential equipment and medication as well as re-organisation of care to ensure close monitoring of postpartum women. Namibia should look at embedding such key strategies for quality improvement into national policy and developing collaborative team-based audit cycles.

\section{Abbreviations}

EOST: Emergency Obstetric Simulation Training; ESMOE: Essential Steps in Managing Obstetric Emergencies; MMR: Maternal Mortality Ratio; PPH: Postpartum haemorrhage; QIC: Quality improvement cycle; WHO: World Health Organization

\section{Acknowledgements}

We would like to express our gratitude to Onandjokwe Hospital management team and to the Head of Obstetrics and Gynaecology

Department for the permission given to conduct this study. We express our appreciation to the audit team members for their commitment during the study period.

\section{Authors' contributions}

TN completed this work for a MPhil degree in Family Medicine at

Stellenbosch University under the supervision of RM. TN conceptualised the 
study, collected data, led the intervention, analysed the data and prepared the manuscript. RM supervised this process, assisted with use of SPSS in data analysis and edited the manuscript. Both authors approved the final manuscript.

\section{Funding}

The study did not require any external grants or funding.

\section{Availability of data and materials}

The datasets analysed during the current study are available from the corresponding author on reasonable request

\section{Ethics approval and consent to participate}

Stellenbosch University's Health Research Ethics Committee (Reference S16/ 06/108) and the Research Committee at Onandjokwe Hospital gave ethical approval for the study. A waiver of informed consent was given to collect data from patient's medical records.

\section{Consent for publication}

Not applicable.

\section{Competing interests}

The authors declare that they have no competing interests.

\section{Received: 23 August 2018 Accepted: 26 November 2019}

Published online: 11 December 2019

\section{References}

1. Fan D, Xia Q, Liu L, Wu S, Tian G, Wang W, et al. The incidence of postpartum hemorrhage in pregnant women with placenta previa: a systematic review and meta-analysis. PLoS ONE. 2017;12(1):e0170194. https://doi.org/10.1371/journal.pone.0170194.

2. Olefile KM, Khondowe O, M'Rithaa D. Misoprostol for prevention and treatment of postpartum haemorrhage: a systematic review. Curationis. 2013;36(1) https://doi.org/10.4102/curationis.v36i1.57.

3. Say L, Chou D, Gemmill A, Tunçalp Ö, Moller A-B, Daniels J, et al. Global causes of maternal death: a WHO systematic analysis. Lancet Glob. Health. 2014;2(6):e323-33. http://www.ncbi.n/m.nih.gov/pubmed/25103301

4. World Health Organization. WHO recommendations for the prevention and treatment of postpartum haemorrhage. Geneva: WHO; 2012. Available from http://apps.who.int/iris/bitstream/10665/75411/1/9789241548502_eng.pdf. Cited 21 th July 2018

5. Lumala A, Sekweyama P, Abaasa A, Lwanga $H$, Byaruhanga R. Assessment of quality of care among in-patients with postpartum haemorrhage and severe pre-eclampsia at St. Francis hospital Nsambya: a criteria-based audit. BMC Pregnancy and Childbirth. 2017;17:29. https://doi.org/10.1186/s12884-016-1219-y.

6. World Health Organization. Health statistics and information systems. Maternal mortality ratio (per 100,000 Live births). Geneva: WHO; 2014. Available from http://apps.who.int/iris/bitstream/10665/112738/1/97892406 92671 eng.pdf. Cited 12th July 2018

7. Woiski MD, Scheepers HC, Liefers J, Lance M, Middeldorp JM, Lotgering FK et al. Guideline-based development of quality indicators for prevention and management of postpartum hemorrhage. Acta Obstet Gynecol Scand. 2015; 94(10):1118-27.

8. The World Bank and the United Nations Population Division: Trends in Maternal Mortality: 1990 to 2013. [Internet]. 2014 [cited 2016 Apr 16]. Available from https://www.unfpa.org/sites/default/files/pub-pdf/97892415 07226_eng.pdf.

9. WHO. Guidelines for the Management of Postpartum Haemorrhage and Retained Placenta. [Internet]. [cited 2016 Mar 6]. Available from http://www. who.int/reproductivehealth/publications/maternal_perinatal_health/ 9789241598514/en/

10. Kuruvilla S, Bustreo F, Kuo T, Mishra CK, Fogstad H, Gupta GR, et al. The global strategy for women's, children's and adolescents' health (2016-2030): a roadmap based on evidence and country experience. Bull World Health Organ. 2016:94(5):398-400. https://doi.org/10.2471/BLT.16.170431.

11. Maswime S, Buchmann E. Causes and avoidable factors in maternal death due to caesarean-related haemorrhage in South Africa. Int J Gynecol Obstet. 2016;134:320-3.
12. Hasegawa J, Sekizawa A, Tanaka H, Katsuragi S, Osato K, Murakoshi T, et al. Current status of pregnancy -related mortality in Japan: a report from the Maternal Death Exploratory Committee in Japan. BMJ Open. 2016;6(3): e010304. https://doi.org/10.1136/bmjopen-2015-010304.

13. Kramer MS, Berb C, Abenhaim H, Dahhou M, Rouleau J, Mehrabadi A, et al. Incidence, risk factors, and temporal trends in severe postpartum haemorrhage. AJOG. 2013;209(5):449 e-1-7. https://doi.org/10.1016/j. ajog2013.07.007.

14. Ononge S, Mirembe F, Wandabwa J, Campell OM. Incidence and risk factors for postpartum hemorrhage in Uganda. Reprod Health. 2016;13:38. https:// doi.org/10.1816/s12978-016-0154-8. PMID: 27080710

15. Gebhardt G, Fawcus S, Moodley J, Farina Z. National committee for confidential enquiries into maternal deaths in South Africa. Maternal death and caesarean section in South Africa: results from the 2011-2013 saving mothers report of the national committee for confidential enquiries into maternal deaths. S Afr Med J. 2015;105(4):287-91.

16. Maswime $\mathrm{S}$, Buchmann E. A systematic review of maternal near miss and mortality due to postpartum haemorrhage. Int J Gynecol Obstet. 2017; 137(1):1-7. https://doi.org/10.1002/ijgo.12096.

17. WHO, UNICEF, UNFPA, World Bank Group, and United Nations Population Division Maternal Mortality Estimation Inter-Agency Group. Maternal mortality in 1990-2015. Available from http://www.who.int/gho/maternal_ health/countries/nam.pdf. [cited 2018 Nov 3].

18. Namibia Demographic and Health Survey 2013. [Internet]. 2014 [cited 2016 Mar 6]. Available from https://dhsprogram.com/pubs/pdf/FR298/FR298.pdf

19. Weeks A. The prevention and treatment of postpartum haemorrhage: what do we know, and where do we go to next? BJOG. 2015;122(2):202-10.

20. Sheldon WR, Blum J, Vogel JP, Souza JP, Gülmezoglu AM, Winikoff B. Postpartum haemorrhage management, risks, and maternal outcomes: findings from the World Health Organization Multicountry Survey on Maternal and Newborn Health. BJOG. 2014;121:5-13.

21. Bartlett L, Cantor D, Lynam P, Kaur G, Rawlins B, Ricca J, et al. Facilitybased active management of the third stage of labour: assessment of quality in six countries in sub-Saharan Africa. Bull World Health Organ 2015;93(11):759-67

22. Woiski MD, Belfroid E, Liefers J, Grol RP, Scheepers HC, Hermens RP. Influencing factors for high quality care on postpartum haemorrhage in the Netherlands: patient and professional perspectives. BMC Pregnancy Childbirth. 2015;15:272. https://doi.org/10.1186/s12884-015-0707-9.

23. Jayanna K, Mony P, Ramesh BM, Thomas A, Gaikwad A, Mohan HL, et al. Assessment of facility readiness and provider preparedness for dealing with postpartum haemorrhage and pre-eclampsia/eclampsia in public and private health facilities of northern Karnataka, India: a crosssectional study. BMC Pregnancy Childbirth. 2014;14:304. https://doi.org/ 10.1186/1471-2393-14-304

24. Tort J, Rozenberg P, Traoré M, Fournier P, Dumont A. Factors associated with postpartum hemorrhage maternal death in referral hospitals in Senegal and Mali: a cross-sectional epidemiological survey. BMC Pregnancy Childbirth. 2015;15:235. https://doi.org/10.1186/s12884-015-0669-y.

25. Boltman-Binkowski $\mathrm{H}$. Assessment of quality of care in the management of postpartum haemorrhage: a review of selected maternal death cases. AJPHERD. 2015;S1(2):549-57.

26. Lubaki JF, Musiti Ngolo J, Maniati LZ. Active management of third stage of labour, postpartum haemorrhage and maternal death rate in the Vanga Health Zone, Province of Bandundu, Democratic Republic of the Congo. Afr J Prim Health Care Fam Med. 2010;2(1):a76. https://doi. org/10.4102/phcfm.v2i1.76.

27. Benedict M, Steinberg WJ, Raubenheimer JE. Knowledge of the management of postpartum haemorrhage by doctors and midwives working in Free State district hospitals. Afr J Nurs Midwifery. 2016; 18(2):146-61

28. Pattinson RC, Makin DJ, Pillay Y, Van der Broek N, Moodley J. Basic and comprehensive emergency obstetric and neonatal care in 12 South African health districts. S Afr Med J. 2015:105(4):256-60.

29. Pattinson RC, Say L, Makin JD, Bastos MH. Critical incident audit and feedback to improve perinatal and mortality and morbidity. Cochrane Database Syst Rev. 2005;4:CD002961.

30. Pattinson R. Reducing direct causes of maternal death. S Afr J Obstet Gynecol. 2013;19(3):59-60.

31. Pattison RC, Hall M. Near misses: a useful adjunct to maternal death enquiries. Br Med Bull. 2003;67:231-43. https://doi.org/10.1093/bmb/dg007. 
32. Mohammadi S, Källestål C, Essén B. Clinical audits a practical strategy for reducing caesarean section rates in general hospital in Teheran, Iran. J Reprod Med. 2012;57(1-2):43-8.

33. Bowie P, De Wet C, McKay J. Criterion audit. In: Bowie P, De Wet C, editors. Safety and improvement in primary care: the essential guide. First. London: Radcliffe Medical Press; 2014. p. 283-93.2.

34. Handbook for national quality policy and strategy: a practical approach for developing policy and strategy to improve quality of care. Geneva: World Health Organization; 2018.

35. Department of Health, South Africa. Guideline for maternity care in South Africa. [Internet]. 2015 [cited 2016 Apr 16]; Available from https://www. health-e.org.za/wp-content/uploads/2015/11/Maternal-Care-Guidelines-2 015_FINAL-21.7.15.pdf.

36. National Department of Health; South Africa. A monograph of the management of postpartum haemorrhage. [Internet]. 2010 [cited 2016 Apr 16]; Available http://www.hst.org.za/sites/default/files/Monograph\%2 OPostpartum\%20Haemorrhage.pdf.

37. Ministry of Health and Social Services, Republic of Namibia. Resources and guidelines. Available from http://www.mhss.gov.na/download. Accessed 30 Aug 2019

38. Frank K, Lombaard H, Pattison RC. Does completion of the essential steps in the managing obstetric emergencies (ESMOE) training package result in improved knowledge and skills in managing obstetric emergencies? SAJOG. 2009;15(3):94. https://doi.org/10.7196/sajog.175.

39. Lumbwe C, Pillay Y, Barron P, Tugendhaft A, Kerber K, Hofman K. Cost and impact of scaling up interventions to save lives of mothers and children: taking South Africa closer to MDGs 4 and 5. Glob Health Action. 2015;8(1): 27265. https://doi.org/10.3402/gha.v8.27265.

40. Willcox M, Harrison H, Asiedu A, Nelson A, Gomez P, LeFevre A. Incremental cost and cost-effectiveness of low-dose, high-frequency training in basic emergency obstetric and newborn care as compared to status quo: part of a cluster-randomized training intervention evaluation in Ghana. Glob Health. 2017:13(1):88.

41. Kruk ME, Gage AD, Arsenault C, Jordan K, Leslie HH, Roder-DeWan S, et al. High-quality health systems in the sustainable development goals era: time for a revolution. Lancet Glob Health. 2018. https://doi.org/10.1016/S2214109X(18)30386-3.

\section{Publisher's Note}

Springer Nature remains neutral with regard to jurisdictional claims in published maps and institutional affiliations.

Ready to submit your research? Choose BMC and benefit from:

- fast, convenient online submission

- thorough peer review by experienced researchers in your field

- rapid publication on acceptance

- support for research data, including large and complex data types

- gold Open Access which fosters wider collaboration and increased citations

- maximum visibility for your research: over $100 \mathrm{M}$ website views per year

At $\mathrm{BMC}$, research is always in progress.

Learn more biomedcentral.com/submissions 